\title{
LA CONSTRUCCIÓN DE OBJETIVIDAD EN LA FILOSOFÍA DE LUDWIG FEUERBACH, EN EL PERIODO 1841 - 1843
}

\author{
Maximiliano Dacuy ${ }^{1}$
}

\begin{abstract}
Resumen:
El propósito del presente trabajo es el de indagar sobre la construcción de objetividad por parte de Ludwig Feuerbach en el periodo 1839 - 1843. Los modos de articularseel objeto, que implica la combinación de dos operaciones por parte del sujeto: como proyección de la esencia objetivada,e introyección en el sujeto del objeto. Ambas conformanla estructura dialógica propia del acto de conocer. A través del análisis textual sobre el corpus de los escritos principales de dicho periodo, intentaremos poner en evidencia: la relación yo - tú como presupuesto de objetividad, sosteniendo no sólo su carácter dialógico, sino también la relevancia para una dialéctica entre empiria y razón,señalada por el mismo Feuerbach; asimismo se pone en cuestión la relación ciencia y vida: en que la objetividad queda enmarcada por vínculos de carácter emocional. Con ello se daría lugar a la religión, y se plantea el dilema entre ciencia - escisión, por un lado; y vida -identidad real, por otro, como un problema abierto en el seno de una filosofía de la identidad.
\end{abstract}

Palabras clave: Conocimiento.Límite.Naturaleza.Realidad. Subjetividad.

\section{THECONSTRUCTIONOFOBJECTIVITYINTHEPHILOSOPHYO- FLUDWIGFEUERBACH, INTHEPERIOD 1841 - 1843}

\begin{abstract}
:
The purpose of this paper is to investigate the construction of objectivity by Ludwig Feuerbach in the period 1839 - 1843. The ways of articulating the object, which involves the combination of two operations by the subject: projection of the objectified essence, and introjection in the subject of the object. Both conform the dialogical structure proper of the act of knowing. Through the textual analysis on the corpus of the main writings of that period, we will try to highlight: the I - Thou relation as objectivity budget, sustaining not only its dialogical character, but also the relevance for a dialectic between empiricism and reason, indicated by Feuerbach himself; likewise, the relationship between science and life is questioned: in which objectivity is framed by emotional ties. This would lead to religion, and the dilemma between science - split, on the one hand; and life-real identity, on the other, as an open problem within a philosophy of identity.
\end{abstract}

Key words:Knowledge.Limit.Nature.Reality.Subjectivity.

\footnotetext{
${ }^{1}$ Doctorando por la Universidad de Buenos Aires (UBA), actualmente profesor y coordinador del departamen-
} to de investigación del Instituto Superior Goya (ISG), Corrientes, Argentina. Mail: mxidacuy@ gmail.com 


\section{LA CONSTRUCCIÓN DE OBJETIVIDAD EN LA FILOSOFÍA...}

Maximiliano Dacuy

Considerar la objetividad en Feuerbach nos lleva realizar algunos interrogantes de carácter general: ¿qué relación existe entre la crítica a la religión y la promoción de la ciencia como modo de abordajegenuino de la realidad?, ¿cuál es la relevancia de la conciencia para la lectura del mundo en su recuperación o restablecimiento de las causas segundas o intermedias?, ¿qué relación tiene el género (Gattung) con la naturaleza y en qué sentido el límite (Grenze, Schranke) permite pensar efectivamente el objeto?

El trabajo se articula en torno a la justificación de una serie de hipótesis que expondré a continuación:

1. Hay una teoría del objeto explícita en Feuerbach (en adelante TO1) con una noción de ciencia acorde a ella. Y dos concepciones de objetividad (Objekt y Gegenstand). Pero hay además una teoría implícita del objeto (en adelante TO2) con su respectiva idea de ciencia, a saber: el sujeto - en su quehacer contemplativo - es la esencia subjetivada del objeto. Subjetivar el objeto, hacerlo esencia consciente, para una conciencia, en esto radica la nociónfeuerbachiana de ciencia desde una concepción materialista. Empero, en TO1 - desde una perspectiva idealista de la ciencia -el objeto es puesto por el sujeto: sin el acto de subjetivar lo no objetivo, lo que es, no es posible la ciencia.

2. En la primera concepción teórica (TO1) el objeto es la esencia objetivada, es la subjetividad representada en el objeto o la representación subjetivada en él, una representación de sí constitutiva del objeto. Aquí la primacía es del sujeto por sobre el objeto (Gegenstand). En la segunda (TO2), el objeto es la presentación de sí sobre el sujeto: puesto que no podría representarse porque no es sujeto; pero se manifiesta, actúa sobre mí, se me presenta; luego lo intuyo. En el periodo señalado, la TO2 no es la mera continuación de TO1, sino su complementación. Quedarnos con la primera formulación implicaría no realizar el pasaje del idealismo al materialismo.

3. En la TO2 el acento está puesto en el objeto, el sujeto es pasivo, porque recién puede serlo: luego de la reducción antropológica y el desmantelamiento del mecanismo de alienación. Es receptivo porque su subjetividad deja determinarse por el objeto y no por sí mismo. Aquí la primacía es del objeto (Objekt). Si en Kant la intuición es aprehensión inmediata de un objeto; en Feuerbach será aprehensión mediata de un

\begin{tabular}{|l|l|l|l|l|}
\hline Q Ponista Dialectus & Ano 5 & n.13 & Agosto - Dezembro 2018 & p. 155-170 \\
\hline
\end{tabular}




\section{LA CONSTRUCCIÓN DE OBJETIVIDAD EN LA FILOSOFÍA...}

Maximiliano Dacuy

objeto: en toda percepción opera la huella de una crítica y restitución de la objetividad. Si el objeto de estudio del idealismo trascendental es el sujeto trascendental, Feuerbach redefinirá el sujeto - que conlleva sureencauzamiento -para construir a partir de allí objetividad. La aparente contradicción entre los supuestos de TO1 y TO2 no es más que un momento del mismo problema, a saber: la identidad del hombre como ser sensible y pensante desde un fundamento natural.

4. La filosofía nueva sólo es posible en la superación de las teorías del objeto. La segunda formulación representa su propedéutica, su modelo y adelanto, su avant premier. No se trata de una filosofía consumada: Tesis “provisionales", Principios de la filosofía “del futuro”. Aquí el punto intermedio será pensar la identidad sujeto objeto (como articulaciones de yo - tú), en pos de la vida. Feuerbach centrará la superación de las teorías del objeto en la idea de vida. El hombre será definido como un ser sensible, pero que vive la sensibilidad. No se agota en el acto de conocer: la tensión del conocer, que implica escisión, nunca decanta en identidad -objetivo último - del hombre consigo mismo, espíritu en la naturaleza.

5. En la primera formulación de la teoría del objeto Feuerbach expresa la posición del idealismo alemán: Fichte y Hegel, sobre todo. En la segunda expresa el materialismo antropológico, y no meramente un materialismo (¿Schelling?).

6. Hay una teoría del conocimiento presentada de modo incipiente en TO2, y no antes -la primera (TO1) representa la ideología: en su verdad y falsedad, en su crítica-. Pero el verdadero conocimiento de algo, objeto, cosa, ser real -en el marco de la filosofía nueva -radicaría en su vivencia. Esto es: en la no-reducción a la estructura sujeto-objeto.

7. La TO1 es crítica y es, en verdad, la antesala de la segunda. La primera es cartesiana, kantiana, idealista; la segunda es empirista, dogmática. Este dogmatismo implica un más acá del idealismo: pero sólo por él es posible. La crítica a Schelling es que no fue lo suficientemente radical.

8. Feuerbach cae en la sacralidad del objeto, se entusiasma con él, lo celebra: interpretación hecha por Marx (Tesis sobre Feuerbach: tesis uno). No obstante, hay momentos en que la contemplación es tal que el sujeto "realiza" al objeto, torna efectiva su realidad, lo expresa espiritualmente. Nunca es su espejo: en todo caso es un

\begin{tabular}{|c|c|c|c|c|}
\hline Q Rovista Dialectus & Ano 5 & n.13 & Agosto - Dezembro 2018 & p. $155-170$ \\
\hline
\end{tabular}


(su) prisma. El sujeto en Feuerbach vive, vivencia el objeto: he aquí el problema respecto al marco teórico en que quiere presentar su teoría, el carácter vago y por momentos grandilocuente de su lenguaje.Realiza el objeto, espiritualiza la realidad (Realität) en actos, hace cultura (Marx diría: hace de lo real un objeto de culto). Éste es el límite de su praxis.

9. En la TO1 el objeto depende del sujeto (véase el poema de Goethe Prometeo), aunque ilusoriamente el sujeto dependa del objeto; en la TO2 el sujeto depende del objeto, aunque ilusoriamente el objeto dependa del sujeto (idealismo, Wissenschaftslehrefichteana).

10. Hay en Feuerbach límites a la subjetividad y a la objetividad. Para lo primero utiliza la noción de género; para lo segundo, la de naturaleza: la clave en ambos es el tú como presupuesto gnoseológico, ético y político. Uno y otro son ilimitados. Infinitud entendida como pluralidad de finitos. Digo género y no esencias genéricas.

11. La conciencia de la propia esencia (género), no implica solamente la objetivación de las perfecciones (esencias genéricas), ni la multiplicidad de individuos (especie articulada en múltiples finitos), sino de todo ente existente, de todo ser allende al hombre -el género (Gattung) es la noción abarcativa, comprehensiva -. De no ser así sería imposible la ciencia, y sólo habría religión. El pasaje a la ciencia implica una crítica a la religión, puesto que su objeto es lo más íntimo a la conciencia humana: consecuencia de esto es que la crítica a la religión sea el presupuesto de toda crítica (Marx), pero desde otros presupuestos.

En La esencia del cristianismo (Das Wesen des Christentums) (1841), Feuerbach $^{2}$ postula su teoría del objeto: este es la esencia objetivada del sujeto (V 28). El sujeto pone el objeto: es su esencia. Pero lo que pone en la objetividad no es un individuo, no se trata de ponerse en sí como individualidad ${ }^{3}$. Feuerbach nos sale al paso de este posible error: lo que objetiva el sujeto es su esencia, su esencialidad (Wesenheit), no su individualidad. Esta esencia es su propio género (Gattung). Una conciencia que exprese carácter indi-

${ }^{2}$ Para nuestra referencia a las obras de Feuerbach utilizaremos la edición de Werner Schuffenhauer, Gesammelte Werke, Berlín, Akademie Verlag, 1970. (Abreviaremos: GW).

${ }^{3}$ De ser esto posible el animal tendría conciencia de sí, pero Feuerbach le reconoce -a lo sumo -un sentimiento de sí (Selbstgefühl). La objetivación de sí del animal sería expresión de una conciencia limitada, pero la conciencia es ilimitada, infinita. Por ello al hablar de conciencia se refiere al ámbito de la infinitud propia del hombre (V 28).

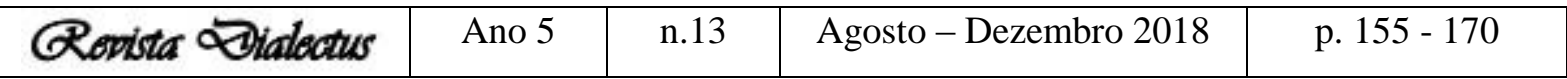


vidual no deja de ser limitada, lo que es un absurdo: puesto que la conciencia es el plano de la infinitud y el individuo es finito. Ahora bien, ¿cualquier objeto responde a esta noción, a saber: de ser la esencia puesta? Feuerbach entiende que sí: incluso el sol y los planetas nos dicen "conócete a ti mismo" (V 34). Los objetos del mundo circundante nos hablan de nosotros mismos, de nuestra capacidad de contemplación teórica y estética. Ahora bien, ¿cómo no caer en un idealismo?,¿O al menos en uno de carácter trascendental, que no se reduzca al mero reconocimiento de la realidad exterior, resaltando la función constitutiva del sujeto?En el Feuerbach de 1841 hay una clara postura sobre el papel del sujeto no sólo como fundamento del conocimiento, sino como creador de objetos divinos y científicos (IX $143)^{4}$. El objeto no es algo que determine - por decirlo - desde fuera al sujeto, sino que es al revés: algo es objeto porque es puesto como esencia por parte del sujeto, sea referido a sí como a lo otro de sí, sea como yo o como tú ${ }^{5}$. Pero en este poner (setzen) la esencia como género, hay que hacer una distinción: lo que el hombre pone como género y es su esencia es la esencia genérica (Gattungswesen). Ella es infinita porque comprehende perfecciones, y aquí reside la divinidad de lo genérico: Dios es amor porque el amor es perfección, es omnipotente porque la voluntad es un carácter esencial de lo humano; es omnisciente porque la razón es constitutiva de humanidad. Pero el orden se trastoca cuando se conglomeran en

${ }^{4}$ Vemos al respecto esta idea en la recensión a la obra de Reiff "El comienzo de la filosofía" ("Anfang der Philosophie"), escrita en 1841: "El cometido de la ciencia consiste, sobre todo, precisamente no en recoger [aufzuheben] aproximadamente el objeto - ¡Dios nos salve! -sino en hacer objetivo lo que no es objetivo" (las bastardillas son del autor [tr. Santiago Santillán Zabaljauregi]).

${ }^{5}$ Althusser recoge en Feuerbach dos acepciones del término objetividad. En la primera (Gegenstand), el objeto es producto de una operación cognitiva del sujeto. Esta primera noción es la determinante en TO1 y es propia de la etapa idealista. Pero hay otra concepción de objetividad, la que entiende que el objeto ( $\mathrm{Ob}$ jekt) es lo que se opone al sujeto y lo determina (afín a TO2). Si bien Feuerbach lo expone así [IX 310) en Principios de la filosofía del futuro (Grundsätze der Philosophie der Zukunft) (1843) esto no significa, como lo entiende Althusser, que Feuerbach traiciona la distinción al referirse al sol y los planetas como objetivaciones de la esencia humana sino que -suponiendo la hipótesis de que en La esencia del cristianismo no hay una concepción materialista del objeto -la objetividad se construye únicamente desde el sujeto. Esto es: Feuerbach hace la distinción después (1843), en un momento precisamente materialista de su pensamiento, en que el objeto -como ser real, sensible, concreto -determina el pensar, el sujeto, la conciencia. Pero no es un repentino cambio de parecer, es una cuestión metódica: Feuerbach pasa al objeto luego de reconquistar, purgar, reconstituir el sujeto a través de la crítica ideológica. Desde otra perspectiva, Althusser considera que en el caso descrito más arriba se presenta una ambigüedad adrede, como es habitual en Feuerbach; pero en verdad, hace alusión a dos concepciones de objetividad que dan cuenta de un momento preferentemente idealista por sobre otro en que prima una perspectiva materialista. Por supuesto, nunca hay una escisión tajante en Feuerbach, nunca hay algo así como un primer y un segundo Feuerbach: idealista uno, materialista el otro; sino que a través de una tipología del objeto y su consecuente noción de ciencia -tengamos en cuenta que la finalidad de la filosofía es tornarse ciencia del saber acerca del mundo (IX 144) -Feuerbach muestra dos facetas de su pensamiento, dos modos de abordaje. No se pone en cuestión, entonces, la ambigüedad en pos de una superación como sostiene Althusser, al menos no en este caso. FEUERBACH, L., 1960, p. 7.

\begin{tabular}{|l|l|l|l|l|}
\hline Q Povista Dialectus & Ano 5 & n.13 & Agosto - Dezembro 2018 & p. $155-170$ \\
\hline
\end{tabular}


una sustancia los predicados: lo que nos pertenece esencialmente pasa a pertenecer a otro y, por ende, nosotros le pertenecemos, he aquí el carácter alienado de la objetivación. A partir de aquí hay un objeto que prima sobre los otros, y es el que será tema de análisis en prácticamente toda la obra feuerbachiana, a saber: Dios, caracterizado como el objeto íntimo. Ahora bien, ¿cómo se constituye este Dios puesto por el hombre? Hay al menos elementos esenciales que Feuerbach no señala, pero que serán fundamentales para poder dar cuenta de lo que el hombre es: la capacidad de proyectar y la sensibilidad. Aunque, visto en detalle, no son de la misma índole. Podríamos sostener sin contradecirnos que la sensibilidad es una perfección: Dios es sensible, puesto que recibe las plegarias, opera milagros por nosotros, nos hace resucitar de esta muerte que es la vida terrena. Un Dios indiferente sería cruelcomo el dios epicúreo - o, caso que exista por sí y para sí, no tendría influencia en nuestra vida, no tendría sentido dirigirle las plegarias y no podría esperarse nada de él. En nuestra cotidianeidad sería un caput mortuum. Y es algo de lo que el hombre no puede prescindir sin dejar de ser tal. De modo que podríamos considerar la sensibilidad como una perfección humana, claramente a despecho de Feuerbach, que no lo plantea explícitamente. Pero, ¿y la proyección? Por un lado nos remite a Kant, fue él quien expuso en su idealismo trascendental esta capacidad de producir objetos por parte del sujeto, advirtiendode suabuso al sobrepasar los límites de toda experiencia posible, el ir más allá de la sensibilidad. Podríamos, claro está, pensar que la proyección no es otra cosa que una operación de la razón (con Kant), o bien de la voluntad (con Feuerbach): pero en verdad, el sujeto proyecta el objeto como un modo de mediación. Proyectar es mediar el sí mismo del sujeto en lo otro de sí: en un objeto, éste es el sujeto mediado. No se trata, por ende, de una perfección, de un predicado divino, sino de una operación cognitiva que hace posible la objetivación, y con ella la predicación. Pero volvamos al planteo sobre el objeto.

El objeto que el hombre pone sobre sí es o bien Dios o bien el género humano. Pero ambos no pueden convivir (IX 285) ${ }^{6}$ : si el primero es la subjetividad ilimitada y per-

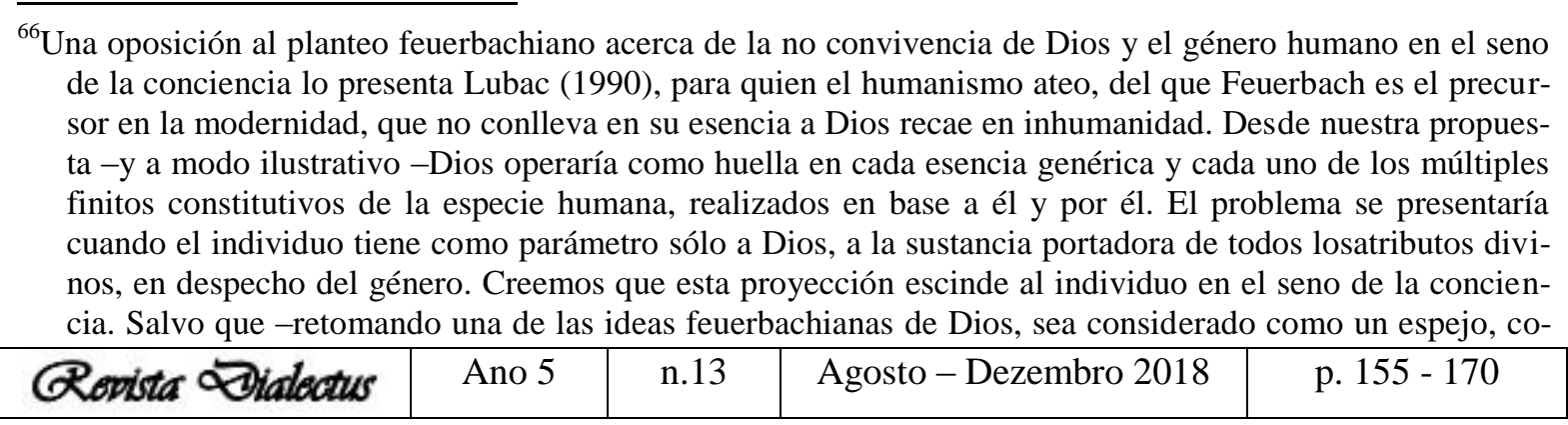


sonalizada; el segundo es la objetivación de los múltiples finitos, la despersonalización de lo múltiple; si Dios es perfecto, el conjunto de finitos es multitudo que expresa perfecciones: pero no en el mismo sentido en que decimos que Dios es perfecto, sino en que consideramos que constituyen la esencia humana.Dios no es la esencia humana, es el tipo de entidad que reemplaza a la esencia humana. Lo que desmonta Feuerbach es el mecanismo de alienación que invierte la relación sujeto objeto. Así, lo que está detrás del objeto Dios es el género humano: el individuo total que ahoga lo colectivo, la comunidad. Feuerbach dirá que la esencia humana existe en la comunidad. Justamente, la creencia de Dios expresa un vínculo total entre él y el individuo. El objeto íntimo expresa la absoluta introversión.

Dios - como objeto de la conciencia -tampoco puede convivir con el objeto de la ciencia: se excluyen mutuamente, y esto es algo que Feuerbach pone de relieve (V 195 y 227). Pero las objetivaciones constitutivas del género (Gattung) pueden convivir en el seno de la conciencia: en tanto infinitud, no es la infinitud de un individuo proyectado y absoluto, sino articulación del yo - tú en el plano de la objetividad: unidad de articulación de lo múltiple, no lo uno proyectado ${ }^{7}$. Esto es: la unidad es lo que contiene la multiplicidad en el seno de la conciencia, pero no es lo uno lo que se proyecta cuando hablamos de género ${ }^{8}$.

mo una primera conciencia. Dios así sería así un momento de la conciencia, por cierto no absoluto. Esta proyección creemos aprobaría Feuerbach, pues aunque esté marcada por el desgarramiento (Zerrissenheit), sería un momento de la autoconciencia, el de la negatividad, central para asumirse el hombre positivamente. Dios es ese pasaje al hombre mismo.

${ }^{7}$ Una objeción a lo expuesto puede ser la siguiente: Dios es uno, es persona; pero es persona trina: la Trinidad es su modo de articulación. Justamente, Feuerbach considera que la Trinidad es la expresión religiosa de la pluralidad del género, siendo divina la esencia del hombre. La infinitud de lo divino en Feuerbach es más pluralidad de infinitud (esencia genérica) y de finitud (especie humana). Por este último Cabada Castro (1975: 62) ve en el género de Feuerbach la indefinidad o mala infinitud y no la infinitud verdadera, en términos hegelianos. Pero el plano de la conciencia es el de la infinitud, la conciencia en sí es infinitud. Si Dios es infinito lo es en la conciencia. Pero si es independiente de la conciencia -como propone el teísmo -entonces debe ser un objeto sensible. Ahora bien, ser existente es ser susceptible de ser conocido, y es conocido si puede percibirse. Por otro lado, si Dios es un objeto que está en nosotros, en nuestra alma o espíritu, en la conciencia, no es más que una expresión de lo humano, puesto que sólo en tanto tenga aspecto humano, que sea un tú, puede conocérsele. Pero la humanidad de Dios es expresión de lo humano, y lo humano como especie es multiplicidad de finitos en el seno de la conciencia. Al determinar el género como especie Feuerbach enlaza la infinitud de las perfecciones (razón, voluntad y corazón) con los individuos de la especie humana, con la humanidad. La amplitud del concepto de género da cuenta de una apertura en el carácter del hombre.

${ }^{8}$ El Dios cristiano es un ser personal, pero así reconozcamos que Dios es uno y trino, que es unidad de multiplicidad, no deja de aparecérsenos la marca de su origen: la fantasía es el organon de la religión, su elemento es la contradicción, a la que se recubre con un halo de misterio, de mística, de más allá del alcance de la razón humana. Pero lo que salva a la contradicción es la imaginación. Con la contradicción cae el fundamento, que no puede dejar de ser en sí contradictorio, esto es: infundado. El análisis de Feuerbach influyó en la teología del s. XX sobre todo. Así, Robinson (1967) entiende a Dios como la profundidad insondable de nuestra existencia, de todo lo que existe. Si bien esta idea la toma de Tillich (1949), no menos

\begin{tabular}{|l|l|l|l|l|}
\hline Gonita Dialectus & Ano 5 & n.13 & Agosto-Dezembro 2018 & p. $155-170$ \\
\hline
\end{tabular}


Así, su marca es la pluralidad (V 276) ${ }^{9}$. En Feuerbach el género siempre es múltiple, es la unidad de la multiplicidad, lo múltiple contenido por lo uno ${ }^{10}$.Ahora bien, si el género humano refiere a un yo - tú constituyente de la objetividad, la ciencia pondrá en evidencia otra modalidad del tú. La clave aquí no es el yo sino el tú - el tú de la intersubjetividad es otro yo; el de la ciencia es un tú sui generis, por decir, un tú radical ${ }^{11}$. El tú feuerbachiano no sólo es el presupuesto de objetividad, sino la posibilidad de darse el yo a través del otro, y reconocerse como tal -en el plano de la intersubjetividad -, plano de la ética y la política. El tú también es el presupuesto de la objetividad del mundo circundante: hay ciencia porque el yo no agota la capacidad de objetivar en la intersubjetividad, éste es el plano del conocimiento.Pero si existe religión es porque Dios puedeocupar todo el lugar de la conciencia. De ahí que la cuestión central en La esencia del cristianismo sea la alienación (Entäusserung). Su finalidad será recuperar el yo. Pero recuperar el yo es recuperar el objeto ${ }^{12}$, la capacidad de objetivarse sin perderse en él, sin alienarse.

cierto es que retoma a Feuerbach para superar la idea de Dios como proyección humana. ROBINSON, J. A., 1967, pp. 89 y ss.

${ }^{9}$ Véase el siguiente pasaje: "En efecto, la esencia del hombre es una, pero esta esencia es infinita; su existencia real es, pues, una infinita variedad que se complementa mutuamente para revelar la riqueza de la esencia. La unidad de la esencia es pluralidad de la existencia”. FEUERBACH, L., 2013, p. 202. Ahora bien, esta pluralidad pueden ser simplemente dos. En la respuesta a las críticas de Stirner (1845) Feuerbach entiende el género como la diferencia entre el varón y la mujer: la unidad del hombre diferenciada por la femineidad y la masculinidad. Véase el siguiente pasaje: "Por género entiendo además la naturaleza del hombre...la naturaleza del hombre existe solamente en la oposición de yo y tú, del hombre y la mujer" (Las bastardillas son del autor). FEUERBACH, L., 1960, p. 229.

${ }^{10} \mathrm{Tal}$ es así que la primera operación que realiza Feuerbach para poner en duda la consistencia del objeto Dios en el seno de la conciencia es la ruptura de la idea en tres elementos. Dios pasa a ser trino: voluntad, razón y corazón, estas son la fuerzas esenciales y constitutivas de lo humano.

${ }^{11}$ El yo - tú es intersubjetividad ya desde Aportes, en que Feuerbach explica con ello la razón y el lenguaje (IX 29), a lo que más tarde será el estar de acuerdo con y en el mundo (V 276), como elementos que dan cuenta de la existencia del tú en el seno del yo: si no existiría este tú, sería imposible la universalidad de la razón, no existiría la posibilidad de compartir el sentido de las palabras, imperaría el mutismo en el seno del sujeto y un perpetuo aislamiento. A este vínculo yo - tú le llama diálogo, interior claro, pero dirá en el mismo texto que la dialéctica es un "diálogo" entre empiria y razón; aquí ya estamos en el plano del conocimiento, en el ámbito objetivo y no ya intersubjetivo. Desde este texto Feuerbach profundizará esta dicotomía en la estructura del tú.

${ }^{12}$ Osier (1968: 23) entiende que en Feuerbach el problema no es el sujeto sino el objeto. La estructura yo - tú es la determinante de toda objetividad, el sujeto es el proceso de este objetivarse. Así, Dios no es un objeto de una subjetividad ilimitada, sino al revés: es la subjetividad ilimitada puesta como objeto, implicando la pérdida de equilibrio de la estructura dual. De darse una objetivación genuina, el sujeto se afirma; de no darse, el sujeto se pierde por falta de limitación, merced al desbarajuste de la estructura yo - tú. Entendemos por objetivación genuina un vínculo dialéctico entre finitud e infinitud, entre individuo y género. La infinitud no está en el yo, sino en el tú: este es el lugar del género.

\begin{tabular}{|l|l|l|l|l|}
\hline Gonita Dialectus & Ano 5 & n.13 & Agosto-Dezembro 2018 & p. $155-170$ \\
\hline
\end{tabular}


El mundo ${ }^{13}$ depende del yo, es el momento idealista de la exposición feuerbachiana, no porque estrictamente lo esté pensando como verdad, sino porque articula su análisis desde este presupuesto ${ }^{14}$ : recordemos que una de las finalidades del proyecto filosófico feuerbachiano es dar cuenta de la objetividad, problemática capital de este periodo,pero para ello debe desembarazar el sujeto de lo no objetivo (gegenstandlich) ${ }^{15}$. En 1841 Feuerbach ya toma claramente partido por la ciencia como modo genuino de abordar la naturaleza. Así, luego de exponer la objetividad determinada por el sujeto, Feuerbach -por decirlo , va al encuentro de ella ${ }^{16}$. El objeto proyectado por el sujeto dará lugar a otra noción de objetividad, no determinada sino determinante: el objeto pasará a tener preeminencia sobre el sujeto: y esto es un paso necesario para articular su materialismo de carácter antropológi$\mathrm{co}^{17}$. Feuerbach ve en la subjetividad ilimitada la pérdida de sí: Dios expresa esa subjetivi-

${ }^{13}$ En La esencia del cristianismo el planteo de la objetividad refiere al mundo y a la naturaleza indistintamente (V 192, 314, 318). Esta equivocidad es propia solamente de esta obra en lo que a hace al uso de estos términos. Luego Feuerbach pondrá el acento en la naturaleza, reservándose los términos sociedad (Gesellschaft) y comunidad (Gemeinschaft), para referirse al ámbito social. El término Estado (Staat) tiene una acepción precisa, y es usado en un solo momento (IX 262), sin confundirse con sociedad ni comunidad.

${ }^{14}$ En Principios Feuerbach reconoce la influencia de Fichte para el yo - tú, de ahí que hagamos referencia a un punto de partida idealista (IX 316). Este yo - tú será el presupuesto de la objetividad. Fichte, con el no-yo, nunca llegó -a los ojos de Feuerbach -a la naturaleza, entendida esta como lo otro del yo (IX 60). No obstante, la noción de límite a la subjetividad por parte del no - yo incluye la salvedad de que en Feuerbach no implica su superación, su eliminación, sino que el tú es parámetro del yo. Existe límite porque existe un tú, existe objeto porque ya está predeterminado en la subjetividad por el tú, existe una conciencia de la naturaleza porque el tú reconoce su influjo y su elemento. Si en Kant la refutación del idealismo se basa en percibir algo permanente por sobre el flujo de representaciones (B 275), en Feuerbach el tú estructural determina la posibilidad de lo otro del yo: es la antesala del objeto. Dios no es más que la colonización del tú en el seno de la conciencia. Véase al respecto el siguiente pasaje de Buber, citado por Robinson (1967): "Cuando el hombre que aborrece el nombre [de Dios] y se cree ser sin Dios, se consagra por entero al diálogo con el Tú de su vida, como un Tú que no puede ser limitado por otro, entonces está dialogando con Dios". (Las bastardillas son del autor). ROBINSON, J. A., 1967, p. 87.

${ }^{15}$ El objeto sensible es un límite al yo, pero Dios es este yo ilimitado, por ello no es límite sino su supresión. Pero tal eliminación es solamente posible en el plano de la fantasía, de la irrealidad.

${ }^{16}$ Cabada Castro (1975:80) sostiene que Feuerbach, luego de destronar a Dios de la conciencia humana debe llenar ese vacío con la naturaleza. Así, su materialismo no sería otra cosa que un gesto desesperado. Véase el siguiente pasaje: "Por otra parte, Feuerbach necesitaba la naturaleza, es decir, algo objetivo y exterior al hombre mismo, para explicar de algún modo por qué el hombre atribuye existencia objetiva e independiente de sí mismo a un "Dios" que -según Feuerbach -no es en realidad sino la propia esencia humana".

${ }^{17}$ Es interesante la postura de Feuerbach sobre el materialismo. Aunque es un tema que tiene un amplio desarrollo, sobre todo en Principios, Feuerbach sostiene una "tercera posición" entre la disputa idealismo materialismo, el primero olvida que el hombre es un ser corpóreo y por ello sensible; el segundo condena al hombre a ser una mera producción de la naturaleza. Pero para Feuerbach, el hombre está en la naturaleza, es producto de ella, pero no se reduce a ella. El hombre tiene espíritu, conciencia, y esto marca una ruptura fundamental con el materialismo francés del s. XVIII. Pero también esta lectura aborda el problema del sujeto - objeto, el problema de la objetivación. Véase el siguiente pasaje: "La realidad del Yo en el objeto es al mismo tiempo la realidad del objeto en el Yo. Si sólo depende de la impresión de los objetos, como opinan el materialismo y empirismo superficiales, entonces también los animales ya podrían, y en verdad deberían, ser físicos; si sólo depende del Yo, fuera de nosotros ningún otro ser diferente del Yo po-

\begin{tabular}{|l|l|l|l|l|}
\hline Q Ponista Dialectus & Ano 5 & n.13 & Agosto - Dezembro 2018 & p. 155-170 \\
\hline
\end{tabular}


dad ilimitada, es la abolición de todo límite. El límite (Grenze, Schranke) ${ }^{18}$ lo pone el mundo, la naturaleza, el objeto: esta lectura se torna recurrente.

Ahora bien, así como la teoría del objeto expresa ${ }^{19}$ la esenciaobjetivada (TO1), veremos que Feuerbach -ya en el periodo 1842 - 1843, sobre todo en Principios -concibe al objeto como "otro yo" (andern Ich) (IX 316), inaugurando con ello otra concepción de la objetividad (TO2), a saber: el objeto es subjetivación de la objetividad. En otras palabras: el objeto actúa sobre el sujeto determinándolo.Es el momento de la intuición. Pero si bien Feuerbach señala la realidad y verdad de lo inmediato, del ser percibido sin ninguna mediación (IX 321),intuir un objeto sí requerirá un tipo de mediación, esto es: en un primer momento de la percepción lo más próximo al sujeto no es el objeto real y efectivo, sino una representación desfigurada de él. La representación es apariencia. Y la apariencia es la manera de concebir del sujeto que proyecta. En un segundo momento de la percepción la inmediatez es producto de una crítica a la apariencia, al objeto imaginario. Estos son los momentos correspondientes a la génesis gnoseológica: al principio el mundo de las cosas es la realidad divina, el mundo creado para el hombre, no es la realidad en el sentido de Realität sino de Wirklichkeit. En vez de partir de lo dado, la realidad es efectividad, realización de la divinidad en el mundo. Pero la crítica del periodo 1839 - 1843 nos lleva a repensar la noción de objeto desde el límite, así como desde el vínculo yo - tú.

El tú es límite estructural del yo, Dios como subjetividad ilimitada no es un tú, sino un yo infinito, pero como mala infinitud, un yo indefinido, en términos hegelianos, porque no se resuelve, sino que es más bien un recorte abstraído del mundo, de la naturaleza, y del hombre mismo, desde una perspectiva teísta. Reencauzado el yo en su vínculo con el tú, revelando un modo genuino de objetivarse el sujeto, la mediación nos devuelve a la

dría recibir las mismas o análogas impresiones que nosotros recibimos de los mismos objetos” (IX 148) (tr. Santiago Santillán Zabaljauregi). Véase al respecto Plejanov (1978) y Schmidt (1975).

${ }^{18}$ Acepciones que Feuerbach distingue en Aportes para la crítica a la filosofía de Hegel (Zur Kritik des Hegelschen Philosophie) (1839), entre barrera (Schranke) y límite (Grenze), siendo la primera de carácter arbitrario, irracional; y el segundo necesario, racional (IX 56), retomando la distinción kantiana pero modificando ligeramente su sentido. En La esencia del cristianismo su utilización será indistinta: el límite será más preciso y dará cuenta de la objetividad, del mundo y la naturaleza en oposición a Dios: concebido como subjetividad ilimitada. En adelante seguirá con esta indistinción.

${ }^{19}$ Reconocemos las resonancias deleuzianas del término, y establecemos cierta similitud que el mismo tiene con la lectura sobre la objetivación de la sustancia en la Ética de Spinoza. Dicha lectura de la ontología spinoziana guarda una similitud con la objetivación feuerbachiana (V 30). Veamos el siguiente pasaje: "La expresión se presenta como una tríada. Debemos la substancia, los atributos, la esencia. La substancia se expresa, los atributos son expresiones, la esencia es expresada". (Las bastardillas son nuestras). DELEUZE, G., 1996, p. 19.

\begin{tabular}{|c|c|c|c|c|}
\hline Qevista Dialectus & Ano 5 & n.13 & Agosto - Dezembro 2018 & p. $155-170$ \\
\hline
\end{tabular}


inmediatez del ser real ${ }^{20}$. En síntesis: el segundo momento es el de la inmediatez, el primero el de la mediación (IX 325). De modo que la TO2 se cierne sobre la TO1: esta restablece la objetivación desde el sujeto(es la parte crítica, negativa); la otra subjetiva el objeto, en el sentido que determina al sujeto, lo limita, lo torna posible, lo sitúa en el mundo y la naturaleza (es la parte constructiva, positiva).Está detrás una concepción antropológica que entiende al hombre como ser real, plantea pues una identidad real en el hombre, en lugar de la identidad abstracta del idealismo alemán ${ }^{21}$. En TO2 el objeto se presenta al sujeto que conoce. Y conocer es contemplar, dar oportunidad al objeto que se presente, que se manifieste en el sujeto. Para ello éste debe prepararse, puesto que el objeto pasa a ser no un correlato del yo sino del tú: la toma de conciencia entre la interdependencia de uno y otro es el presupuesto del conocimiento. El problema con el egoísmo práctico ${ }^{22}$ es que se construye el objeto mediante la expoliación del yo sobre la naturaleza: es el imperio de la técnica, es el dominio que subyuga, y subyuga porque la naturaleza es nada, creada ex nihilo. Si la naturaleza es lo otro del individuo, y es nada; el tú que la contiene en la conciencia lo es también; es así que el yo lo es todo.

Ahora bien, si en TO1 la actividad determina la objetividad, en el plano de la conciencia; en TO2 la actividad es contemplación, como dijimos más arriba: el sujeto da lugar al objeto, el yo da lugar al tú, y se encuentra en él, a diferencia del egoísmo práctico en que reina el desencuentro. La ciencia aquí no será más que la articulación racional del objeto, pero partir de la modalidad en que se presenta: ¿a través del amor, en tanto otro in-

${ }^{20}$ Este camino es también el kantiano. Sabemos que para Kant la intuición es aprehensión sensible de un objeto (A 19). Ahora bien, esta aprehensión es posible mediante las formas puras de la intuición y las categorías. Sin ellas no sólo no hay intuición sino que impera el reino de la cosa en sí.

${ }^{21}$ Si Dios dice: "soy el que soy", y el idealismo alemán: “yo soy yo", Feuerbach dirá: “yo soy tú". No niega el yo, lo afirma en el tú. Y el tú no es otra cosa que los otros yo. La esencia para Feuerbach es comunidad (V 277). Crítico acérrimo de la identidad del idealismo, identidad entre ser y pensamiento, en detrimento del ser, no celebrará un hombre escindido - puesto que sería abstracto en tanto aislado del resto de la naturaleza y de ese modo continuaría alienado -sino que restablecerá la identidad real, del hombre consigo mismo (IX 260). Véase el siguiente pasaje: (...) "ella [la nueva filosofía] es el hombre mismo que piensa -el hombre que es y sabe que es la esencia (Wesen) autoconsciente de la naturaleza, la esencia (Wesen) de la historia, la esencia (Wesen) de los Estados, la esencia (Wesen) de la religión -el hombre que es y sabe que es la identidad real (no imaginaria), absoluta, de todas las oposiciones y contradicciones, de todas las cualidades activas y pasivas, espirituales y sensibles, políticas y sociales". (El subrayado es del autor). FEUERBACH, L., 1969, p. 49. Respecto a la cuestión de la identidad en el idealismo alemán, Plejanov afirma lo siguiente: "En realidad el materialismo reconoce la unidad del sujeto y del objeto, pero de ningún modo su identidad. Era Feuerbach quien lo ha explicado ya con toda lucidez". Y, más adelante: (...) "la unidad del pensar y del ser no puede significar, en modo alguno, su identidad". (El subrayado es del autor). PLEJANOV, Y., 1981, pp. 25 y 27.

${ }^{22}$ Para el egoísmo práctico, véase el capítulo XII de La esencia del cristianismo.

\begin{tabular}{|l|c|c|c|c|}
\hline Ronista Dialectus & Ano 5 & n.13 & Agosto-Dezembro 2018 & p. 155-170 \\
\hline
\end{tabular}


dividuo?, ¿a través de la intuición racional, en tanto cosa?, ¿el intuirse a sí mismo en el sujeto que se piensa, que se siente? Modalidades de conocimiento, saberes que se articulan. Sí está claro que la ciencia se trastoca en vivencia. Feuerbach -sobre todo a través de la dimensión de la sensualidad -va mellando la diferencia entre ser y pensamiento, otrora presupuesto de toda crítica ${ }^{23}$. El objeto se subjetiviza; la contraparte es el sujeto que se objetiviza, no quiere decir esto que lo hace en el sentido de TO1, sino que es un receptor, determinado más bien que determinante. Estamos aquí en las antípodas del idealismo alemán, punto de partida del periodo - por decirlo -clásico del pensamiento feuerbachiano ${ }^{24}$, y objeto de este análisis. Si el idealismo descubre el yo, Feuerbach descubre el tú ${ }^{25}$. Pero para operar el tú feuerbachiano precisa del yo, éste le da su lugar: por cierto, no el lugar del yo. Si el tú es otro yo lo es porque dicha operación supone un yo. Aunque insistacon el carácter activo de la contemplación no hay que olvidar que se trata de una actividad, y por ende, del yo $^{26}$. Solamente el yo puede operar el pasaje al tú, y con ello Feuerbach está en deuda-que siempre reconoce -con el idealismo alemán, sobre todo con Fichte (IX 316). Fichte, Hegel $^{27}$, ¿Schelling? La posición feuerbachiana respecto a éste es un tema aparte, pero al que haremos breve alusión. Feuerbach ve en la filosofía de Schelling:"una planta exótica -la vieja identidad oriental en tierra germánica". ${ }^{28}$ (IX 16).

Este punto de vista inicial será más preciso:

Como se sabe, al principio Schelling no quería más que seguir la vía opuesta o contraria al Idealismo. La Filosofía de la Naturaleza no fue de hecho al comienzo,

\footnotetext{
${ }^{23}$ Es la lectura que tiene en Aportes (IX 51) y marca su diferencia con el idealismo alemán, respecto de la crítica: "[en relación al idealismo alemán] La condición fundamental de toda crítica, la diferencia entre lo subjetivo y lo objetivo, había desaparecido". FEUERBACH, L., 1974, p. 52.

${ }^{24}$ Véase al respecto ALTHUSSER, L., 2011, P. 58 y XHAUFFLAIRE, M., 1970, P. 149.

${ }^{25}$ Véase el comentario al respecto de Martín Buber: "Marx no ha acogido en su concepto de la sociedad el elemento de la relación real entre el yo y el tú, realmente diferentes, y por eso ha opuesto a un individualismo ajeno a la realidad un colectivismo no menos irreal. Pero Feuerbach ha iniciado con aquel pasaje ese descubrimiento del tú que se ha calificado de "revolución copernicana" del pensamiento moderno y de “acontecimiento elemental". BUBER, M., 1949, p. 58.

${ }^{26} \mathrm{La}$ actividad contemplativa feuerbachiana es un presupuesto -desde la lectura de Plejanov -de la praxis en Marx. Véase al respecto el siguiente pasaje: (...) "Feuerbach hace resaltar el hecho de que nuestro "yo" conoce el objeto solamente exponiéndose a su acción; sin embargo, Marx replica: nuestro "yo" conoce el objeto actuando a su vez sobre él...Es cierto que para la defensa de Feuerbach podía alegarse que en el proceso de nuestra acción sobre los objetos, nosotros no conocemos sus propiedades sino en la medida en que ellos actúan a su turno sobre nosotros. En los dos casos, el pensamiento está precedido por la sensación; en ambos experimentamos, en primer lugar, las propiedades de los objetos, y no es sino después que pensamos en ellos". (Las bastardillas son del autor). PLEJANOV, Y., 1981, p. 20.

${ }^{27}$ Más allá de reconocerlo como su maestro, Feuerbach considera la moderna filosofía alemana desde Hegel, quien introduce la diferencia en el seno de la identidad. Más adelante, en nota al pie, Feuerbach dirá "sin diferencia no hay verdad".

${ }^{28}$ FEUERBACH, L., 1974, p. 15.
}

\begin{tabular}{|l|l|l|l|l|}
\hline Q Povista Dialectus & Ano 5 & n.13 & Agosto - Dezembro 2018 & p. $155-170$ \\
\hline
\end{tabular}


sino el Idealismo dado vuelta y por ello el tránsito del Idealismo a la Filosofía de la Naturaleza no fue difícil. El idealista reconocía vida y razón también en la Naturaleza, pero sólo como su propia vida, como su propia razón. Lo que veía en ella era lo mismo que él le había introducido; además, retomaba en sí mismo lo que él había concedido a la naturaleza: la naturaleza es el yo objetivado, el espíritu que no ve fuera de sí mismo ${ }^{29}$ (IX 46).

Más allá de este juicio severo sobre esta especie de idealismo naturalista reconociendoel oxímoron de semejante construcción- Feuerbach le atribuye una intención superadora respecto de la filosofía de Fichte, señala su positividad como filosofía de la naturaleza (IX 50). Pero, aunque se lo considerase sucontinuador -Marx le pide un artículo para que dé su opinión sobre la filosofía de Schelling ${ }^{30}$ - Feuerbach se separa ya en Aportes de su filosofía de la naturaleza, así como de la noción de libertad (V 320) ${ }^{31}$.Y si toma distancia del idealismo también lo hará del materialismo francés, no obstante su influencia ${ }^{32}$, puesto que se pierde en este último la idea de libertad, fundamental para Feuerbach, y aporte central del idealismo desde $\mathrm{Kant}^{33}$.Que el yo dé lugar al tú en la percepción de un objeto no conlleva a un espontaneísmo de las categorías - al modo kantiano -sino que implica un acto de libertad y toma de conciencia. Recordemos la percepción de un objeto presupone una mediación crítica, luego de la cual se da el abordaje desde la inmediatez. La inmediatez es un derecho que se conquista, luego de recobrar el yo perdido en el objeto absoluto.

Empero, Feuerbach es un filósofo de la vida, la ciencia es el modo genuino de abordar objetos, pero la vivencia establece una identidad más allá de la dicotomía. Cuando la propuesta es la de una identidad real en el hombre, no hace referencia a la ciencia, sino a la vida. Si el sujeto y objeto antes se separaban para romper la identidad abstracta del idealismo, en la identidad real el sujeto es objeto. Uno y otro son y no lo mismo: el objeto ad-

\footnotetext{
${ }^{29}$ Ibídem, p. 46.

${ }^{30}$ Carta citada por PLEJANOV, Y., 1981, p. 93.

${ }^{31}$ Véase la siguiente nota de La esencia del cristianismo: "En su libro sobre la libertad, Schelling explica este enigma [enigma de lo indeterminado de la libertad humana] por una autodeterminación realizada en la eternidad, es decir, antes de esta vida. ¡Qué hipótesis fantástica e ilusoria! Pero lo fantástico y hasta lo fantástico infantil y absurdo es el misterio íntimo de la llamada filosofía positiva, de estos "profundos" especuladores religiosos. Cuanto más falsas son las cosas, más profundas”. FEUERBACH, L., 2013, p. 234.

${ }^{32}$ Respecto de la importancia del materialismo para Feuerbach, véase Plejanov (1981) y Schmidt (1975).

${ }^{33}$ Véase el planteo de Holbach, tal vez el exponente máximo del materialismo francés, quien no reconoce la posibilidad de libertad en el hombre: "De todo lo que acabamos de decir en este capítulo resulta que el hombre no es libre un solo instante de su vida; que no es dueño de la conformación que ha recibido de la Naturaleza, ni tampoco de sus ideas o causas que obran sobre él contra su voluntad; que no es dueño de no amar ni de no desear lo que le parece amable; de no deliberar cuando no está seguro de los efectos que los objetos producirán en él; de no escoger lo que le parece más ventajoso, y, en fin, que no es dueño de obrar de ningún otro modo sino del que obra". HOLBACH, 1906, p. 182.
}

\begin{tabular}{|l|l|l|l|l|}
\hline Gevista Oialectus & Ano 5 & n.13 & Agosto-Dezembro 2018 & p. 155-170 \\
\hline
\end{tabular}


quiere características del sujeto, asimismo el objeto. El objeto actúa sobre la pasividad del sujeto, aunque dicha pasividad es producto de un acto deliberado del yo en la acción contemplativa. Hasta aquí no hay inconvenientes, pero si pensamos desde el amor, el entusiasmo irrumpe en su abordaje. Es así que al atribuir categorías de uno a otro, y con el entusiasmo de vivir el objeto, se da nuevamente lugar a la religión, que viene de la mano de la nueva filosofía. Feuerbach parece pensar en una filosofía para la vida, en que el conocimiento -y por ende la ciencia - es una parte, fundamental, pero no la única. Vivir, vivenciar el conocimiento, será problemático. Hay algo del orden de lo dionisíaco que opera en el acto de conocer, y esto es una marca de Feuerbach: por momentos la contemplación teórica se confunde con la estética. Empero, vivir es ser en la exuberancia de la naturaleza, realizarse y realizarla. El hombre integral, como totalidad, es lo central en el último periodo analizado, de ahí la idea de superar la ciencia como modo genuino por excelencia en el abordaje del objeto $^{34}$. En la confusión de caracteres entre el sujeto y el objeto, en este complejo de sujeto - objeto, la ciencia da lugar otra cosa que no es ella. Vivir es unir, no separarse. Pero la ciencia implica la separación de ser y pensamiento, de sujeto y objeto.

Por ello, Feuerbach supera en la vivencia la ciencia, y con ella las teorías del objeto. Postura acorde con una nueva religión más que con una nueva filosofía o, a lo sumo, una nueva concepción del mundo (Weltanschauung). Esto es así no sólo por la intención de pensar al hombre en su integralidad, sino en reedificar el yo - tú desde un vínculo de reconocimiento de la naturaleza. Reconocerlalleva a pensar la escisión en un ámbito de relatividad. Sería difícil pensar con Feuerbach en la preeminencia de la técnica, de la tecnología, que no es otro modo de despotismo del yo, ya denunciado en sus reflexiones sobre el egoísmo práctico. Es la misma época en que se perfila el positivismo como concepción superadora de la religión y la metafísica ${ }^{35}$. Desde el lugar que le asigna en la ciencia, la ética y la política al tú como presupuesto de la subjetividad y, por ende, de toda construcción de objetividad, la insistencia de una cosmovisión basada en la integralidad es más bien

\footnotetext{
${ }^{34}$ Véase el siguiente pasaje del final de Principios (IX 338): "La verdad no existe en el pensar, no existe en el saber para sí mismo. La verdad es solamente la totalidad de la vida y de la esencia (Wesen) humanas". (Las bastardillas son del autor). FEUERBACH, L., 1969, p. 150.

${ }^{35}$ Augusto Comte publica el Discurso sobre el espiritu positivo en 1844.

\begin{tabular}{|l|l|l|l|l|}
\hline Gonita Dialectus & Ano 5 & n.13 & Agosto-Dezembro 2018 & p. $155-170$ \\
\hline
\end{tabular}
}


un logro, a fuer de considerar la crítica de la religión y la ciencia -que parten de un fundamento natural-como formasde la praxis ${ }^{36}$.

\section{REFERENCIAS:}

ALTHUSSER, Louis. La revolución teórica de Marx. México: Siglo Veintiuno Editores, 2011.

BUBER, Martín. ¿Qué es el hombre? México: Fondo de Cultura Económica, 1949.

CABADA CASTRO, Manuel.El humanismo premarxista de Ludwig Feuerbach. Madrid:Biblioteca de Autores Cristianos, 1975.

DELEUZE, Giles.Spinoza y el problema de la expresión. Madrid: Muchnik Editores, S. A., 1996.

FEUERBACH, Ludwig.Aportes para la crítica de Hegel. Buenos Aires: Editorial La Pléyade, 1974.

Gesammelte werke. Berlín: Akademie Verlag, 1970.

.La esencia del cristianismo. Madrid: Editorial Trotta, 2013.

.La filosofía del futuro. Buenos Aires: Ediciones Calden. 1969.

.Manifestes philosophiques. Paris: Presses Universitaires de France, 1960.

HELLER, Ágnes. Crítica de la ilustración. Barcelona: Ediciones Península, 1999.

HOLBACH, Barón de. Sistema de la naturaleza. Buenos Aires: Serafín Ponzinibbio Editor, 1906.

LUBAC, Henri de.EI drama del humanismo ateo. Madrid: Ediciones Encuentro, 1990.

OSIER, Jean-Pierre. “Présentation”, a L’essence du Christianisme. Paris: Maspero, 1968.

${ }^{36}$ Es verdad que -como dice Heller (1999: 111)- en Feuerbach brilla por su ausencia el término "trabajo", por ello no puede llegar a concebir la praxis tal como la entienden Marx y Engels. No obstante ello, que es una de las críticas centrales de las Tesis y con la que estamos de acuerdo, Feuerbach sí contribuye al concepto de praxis, sobre todo al fundamentar desde el hombre la actividad humana que, a más de su carácter contemplativo, falta el paso que la lleva a su realización en la transformación de la naturaleza. Esto es: falta desplegar -faena que llevará adelante Marx -la dimensión dialéctica de la praxis. A saber: el sujeto que actuando sobre el objeto- lo transforma y se transforma a sí mismo.

\begin{tabular}{|l|l|l|l|l|}
\hline Qevista Dialectus & Ano 5 & n.13 & Agosto - Dezembro 2018 & p. 155 - 170 \\
\hline
\end{tabular}




\section{LA CONSTRUCCIÓN DE OBJETIVIDAD EN LA FILOSOFÍA...}

Maximiliano Dacuy

PLEJANOV, Yuri.Cuestiones fundamentales del marxismo. México: Premia Editora, 1981.

ROBINSON, John A. Sincero para con Dios. Barcelona: Ediciones Ariel, S. A., 1967.

SCHMIDT, Alfred.Feuerbach o la sensualidad emancipada. Madrid: Taurus Ediciones, S. A., 1975.

XHAUFFLAIRE, Marcel.Feuerbach et la théologie de la sécularisation. Paris: Les Éditions du Cerf, 1970. 